\title{
Development and allometric growth patterns during early larval stages of the spotted sand bass Paralabrax maculatofasciatus (Percoidei: Serranidae)
}

\author{
RENATO PEÑA and SILVIE DUMAS \\ Unidad Piloto de Maricultivos, CICIMAR-IPN, La Paz, B.C.S. 23096, Mexico, E-mail: blacklarvae@ hotmail.com
}

\begin{abstract}
SUMMARY: We describe the allometric growth patterns of Paralabrax maculatofasciatus larvae raised under culture conditions. From hatching to day 30 , ten to fifteen larvae were sampled each day and measured using digital photograph software. Morphometric measurements included total length, head length, body length, tail (post anal) length, head depth, body depth, muscle height, tail depth, mouth length and eye diameter. Allometric growth was modeled by a power function and patterns in allometry were described by the growth coefficient (power function exponent). Based on the changes in the growth coefficients we can infer changes in ontogenetic priorities related to developmental stages of the spotted sand bass. During the yolk sac and preflexion stages (TL interval $=1.57$ to $4.38 \mathrm{~mm}$ ) there is an evident priority to enhancing the feeding and swimming capabilities by promoting accelerated growth in the head and tail length. During the flexion stage (TL interval $=4.89$ to $7.54 \mathrm{~mm}$ ), there is a major decrease in the growth coefficients, indicating a change in growth priorities. At the end of the postflexion stage there is an evident tendency to isometry for all the growth coefficients. The present results support the hypothesis of differential growth patterns for primary functions during early ontogeny.
\end{abstract}

Keywords: allometric growth, larval development, spotted sand bass, Paralabrax maculatofasciatus.

\begin{abstract}
RESUMEN: DESARROLLO Y PAUTAS DE CRECIMIENTO ALOMÉTRICO DURANTE LOS PRIMEROS ESTADIOS LARVARIOS DE LA CABRILLA AREnera Paralabrax maculatofasciatus (Percoidei: Serranidae). - Este estudio describe los patrones de crecimiento alométrico de Paralabrax maculatofasciatus en cultivo. Desde la eclosión hasta los 30 días, de diez a quince larvas fueron recolectadas y medidas utilizando un software de fotografía digital. Las mediciones incluyeron longitud total, longitud de la cabeza, longitud del cuerpo, longitud de la cola (post anal), altura de la cabeza, del cuerpo, muscular, y de la cola, longitud de la boca y diámetro del ojo. Los patrones de crecimiento alométrico fueron calculados como una función potencial. Sobre la base de los cambios en los coeficientes de crecimiento se infieren cambios en las prioridades ontogenéticas relacionadas con los estadios de desarrollo. Durante los estadios de larva vitelina y preflexión (TL intervalo $=1.57-4.38 \mathrm{~mm}$ ) existe una evidente prioridad para incrementar las capacidades alimenticias y natatorias. Durante la etapa de flexión (TL intervalo $=4.89-7.54$ $\mathrm{mm}$ ) se observa un cambio en las prioridades de crecimiento. Al final de la etapa de postflexión existe una evidente tendencia a la isometría en todos los coeficientes de crecimiento. Estos resultados apoyan la hipótesis de patrones diferenciales de crecimiento para funciones primordiales durante la ontogenia inicial.
\end{abstract}

Palabras clave: crecimiento alométrico, desarrollo larvario, cabrilla arenera, Paralabrax maculatofasciatus.

\section{INTRODUCTION}

Early ontogeny of most larval fishes is characterized by drastic changes involving most organs and systems. These changes determine the physiological and behavioral capabilities during development. As the smallest free-living vertebrate, marine fish larvae are subject to high environmental pressures manifested in high mortality rates. Factors like starvation and predation have been proposed as some of the main regulators of survival during the larval period, affecting recruit- 
ment and year-class strength in wild populations (Bailey and Houde, 1989) and seed quality under culture conditions (Peña and Dumas, 2005).

Allometric growth during early larval development has been observed in different teleost groups (Osse and van den Boogaart, 2004). It is considered an adaptive response to counteract environmental pressures, increasing the probability of survival and growth during early development by producing changes in body form due to differential growth (Fuiman, 1983) of organs and systems involved in primary functions (i.e. feeding, respiration and locomotion) rather than organs which are a lower priority for survival (Osse and van den Boogaart, 1995). The determination of relative growth patterns during early development can contribute to fisheries management and aquaculture by characterizing normal growth patterns under certain conditions and optimizing rearing protocols if abnormalities in larval development are detected. The objective of this study was to test the hypothesis of differential growth during larval development by describing the allometric growth patterns of the spotted sand bass larvae reared under culture conditions.

\section{MATERIALS AND METHODS}

Larvae were obtained by spontaneous spawning of spotted sand bass broodstock held under controlled conditions $\left(23^{\circ} \mathrm{C}, 12 \mathrm{~L}\right.$ : $12 \mathrm{D}$ photoperiod) (Rosales-Velazquez, 1997). Newly hatched larvae were placed in a closed recirculating system that has been described previously (Alvarez-González et al., 2001). Culture conditions were $25 \pm 0.8^{\circ} \mathrm{C}$, $35 \pm 1 \mathrm{psu}, 6.49 \pm 0.15 \mathrm{mg} / \mathrm{l}$ dissolved oxygen, 12L:12D artificial photoperiod and light intensity of 500 lux at the water surface.

Larvae were fed from mouth opening (day 2) with Selco ${ }^{\mathrm{TM}}$ (Artemia, systems, Ghent, Belgium) enriched rotifers Brachionus plicatilis at a density of 5 rotifers $\mathrm{ml}^{-1}$ until day 13 . Selco ${ }^{\mathrm{TM}}$ enriched Artemia nauplii were fed from day 12 to day 19 at a density of 5 nauplii $\mathrm{ml}^{-1}$. Juvenile Artemia were fed to the larvae from day 18 until day 30 at a density of 0.1 juvenile $\mathrm{ml}^{-1}$. From hatching until day 30, random samples of 10 to 15 larvae were taken each day prior to feeding during the morning. Sampled larvae were anesthetized (MS-222, $35 \mathrm{mg} \mathrm{ml}^{-1}$ ) and digital photographs were taken using digital image analysis software (Image Pro

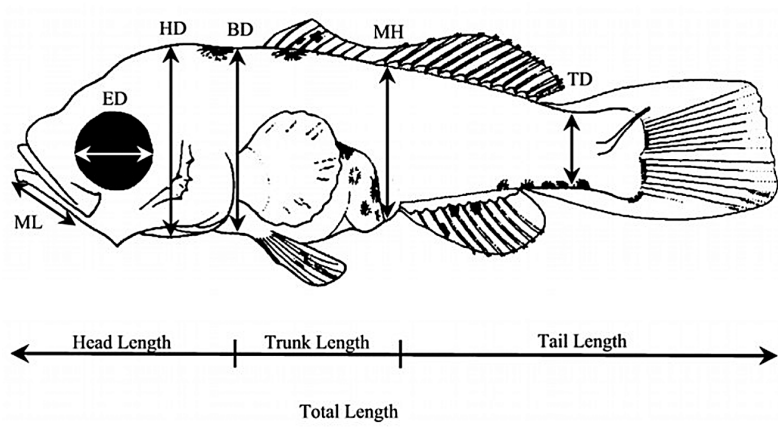

FIG. 1. - Morphometric characters measured in the spotted sand bass larvae. BD, body depth; ED, eye diameter; HD, head depth; MH, musculature height; ML, mouth length; TD, tail depth.

Plus v5, Media Cybernetics, MD, USA). Developmental stages were identified according to Kendall et al., (1984) as yolk-sac larvae (right after hatching and until the complete depletion of the yolk-sac), preflexion larvae (from mouth opening to the start of the flexion of the caudal tip of the notochord), flexion larvae (from the flexion of the notochord to the appearance of the hypural plate), postflexion larvae (from the appearance of the hypural plate to the observation of a pigmentation pattern similar to the adults) and juvenile.

On each digital photograph, several body proportions (see Fig. 1) associated with feeding and locomotion were measured to the nearest 0.01 $\mathrm{mm}$. These measurements were: body depth at the pectoral fin level (BD); trunk length from the end of the operculum to the anus (TRL,); eye diameter in an anterior-posterior plane (ED); head depth from the bottom of the mouth cavity to the top of the head (HD); head length from the tip of the snout to the end of the operculum (HL); muscle height at anus level (MH); mouth (maxilla) length (ML); tail (post anal) length (TAL); tail depth at the caudal peduncle level (TD); and total length form the tip of the snout to the end of the caudal fin (TL). Dead and abnormal specimens (presence of malformations) were excluded from the analysis.

Growth patterns during the developmental stages of the spotted sand bass were modeled by a power function of TL and the patterns in allometry were described by the growth coefficient (i.e. power function exponent) in the equation $\mathrm{Y}=a \mathrm{X}^{b}$, where $\mathrm{Y}$ is the dependent variable (measured character) and $X$, the independent variable (TL), $a$ is the intercept and $b$, the growth coefficient. Isometric growth occurred when $b=1$. A positive allometric growth occurred when $b>1$ 
and a negative allometric growth when $b<1$.

In addition, linear regressions were performed on log-transformed data (TL as independent variable) and the inflection points were calculated for $\mathrm{HD}, \mathrm{BD}, \mathrm{MH}, \mathrm{TD}, \mathrm{ML}$ and ED. Inflection points are the $\mathrm{X}$ values where the slope changes. The inflection points were calculated according to van Snik et al. (1997), in which linear regressions were calculated for Xmin to Xintermediate and for Xintermediate to Xmax and then compared by $\mathrm{t}$-tests to evaluate if the two slopes $(b)$ for XminXintermediate and Xintermediate-Xmax differed significantly. The Xintermediate value that iteratively showed the largest $t$ from the comparison was defined as the inflection point. Xintermediate was defined as a value that ranged iteratively from $\mathrm{X} \min +2$ to $\mathrm{X} \max -2$.

\section{RESULTS}

\section{Development}

Growth of the spotted sand bass followed an exponential curve (Fig.2). After hatching, five developmental stages were evident during the studied period: yolk-sac larvae, preflexion larvae, flexion larvae, postflexion larvae and juvenile. The first three stages are characterized by drastic changes in larval form. After hatching, the endogenous nutrition period lasted for two days, and the average TL during this stage ranged from $1.57 \pm 0.06 \mathrm{~mm}$ (mean \pm std. dev.) at hatching to $2.55 \pm 0.08 \mathrm{~mm}$ at day 2. Yolk-sac larvae were translucent and lacked

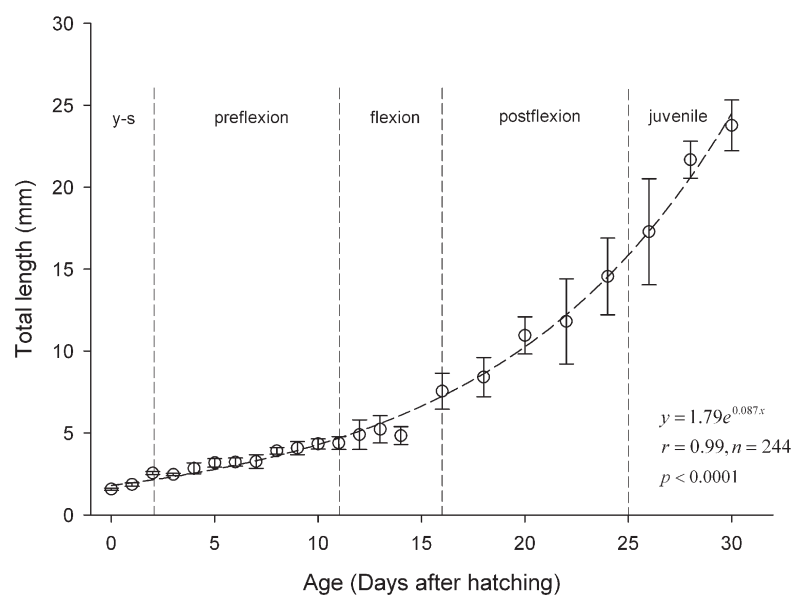

FIG. 2. - Growth of the spotted sand bass larvae from hatching until day 30 . Each point represents the mean \pm std. dev. $y-s=$ yolk-sac larvae. all major organs and systems. An unpigmented eye and a finfold covering the body from the dorsal area of the head to the ventral area of the yolk sac were observed. The finfold was wider in the dorsal part of the trunk and narrowed in the caudal region. Auditory capsules and otoliths were visible in the posterior head region. A single oil globule was present (average diameter $0.13 \pm 0.06 \mathrm{~mm}$ ) in the anterior lower region of the yolk-sac. The digestive tract was an undifferentiated tube in the dorsal posterior region of the yolk-sac. Melanophores were observed in the ventral caudal region and in the dorsal trunk region.

The preflexion stage began at first feeding (day 2) (average TL $2.55 \pm 0.08 \mathrm{~mm}$ ) and ended around day 11 (average TL $4.38 \pm 0.39 \mathrm{~mm}$ ). At the onset of the preflexion stage, the eye became fully pigmented and the mouth and anus opened. The yolksac and oil globule were almost depleted. Mucosae folds and an intestinal valve were observed in the digestive tract. Branchial arches were observed from days 5-6. At day 6 (average TL $3.22 \pm 0.24$ $\mathrm{mm}$ ), larvae initiated gas bladder inflation by swallowing air directly from the water surface. A coiled digestive tract was evident from days 8-9 (average TL $4.08 \pm 0.40 \mathrm{~mm}$ ). The number of melanophores increased in the ventral and dorsal regions of the digestive tract and in the ventral region of the axial muscle. The finfold started to narrow in the dorsal trunk and anal fin regions.

The flexion stage started from day 12 (average TL $4.89 \pm 0.90 \mathrm{~mm}$ ) and continued until day 16 (average TL $7.54 \pm 1.09 \mathrm{~mm}$ ). At day 12, most of the larvae showed a $45^{\circ}$ upward turn of the notochord tip. The finfold narrowed in the caudal peduncle and the first caudal fin rays appeared in the ventral region of the notochord tip. Pelvic buds were evident from day 12 . At day 16 , notochord flexion was completed. The finfold was completely absorbed. Pelvic, anal, and dorsal fins with pigmented rays were observed.

After these stages, less drastic changes were observed. The postflexion stage was observed from day 18 (average TL $8.41 \pm 1.19 \mathrm{~mm}$ ) to day 22 (average TL $11.80 \pm 2.59 \mathrm{~mm}$ ). Fin elements were evident in the caudal, dorsal, pelvic and anal fins. Body pigmentation increased in the middle of the body. The juvenile stage was observed from day 24 (average TL $14.55 \pm 2.34$ ), when the typical juvenile pigmentation pattern was first observed, and continued until day 30 . 


\section{Growth patterns}

During the endogenous nutrition period, head and tail length had positive allometric growth in relation to TL ( $b=1.24, r^{2}=0.98$ and $b=1.18$, $r^{2}=0.99$ respectively), while the trunk length showed negative allometric growth $\left(b=0.61, r^{2}\right.$ $=0.98$ ) (Fig. 3a). In the preflexion stage, the head length showed positive allometric growth $(b=1.7$, $\left.r^{2}=0.99\right)$; however, trunk and tail length showed negative allometric growth $\left(b=0.74, r^{2}=0.98\right.$ and $b=0.85, r^{2}=0.99$ respectively) (Fig $3 b$ ). During the flexion stage, the head length still showed positive allometric growth $\left(b=1.15, r^{2}=0.99\right)$, while growth in the trunk length was negatively allometric $\left(b=0.87, r^{2}=0.97\right)$. Tail length growth in the flexion stage was isometric $\left(b=0.96, r^{2}=\right.$ 0.99) (Fig. 3c). In the postflexion-juvenile stage, growth of the head, tail and trunk length was isometric $\left(b=0.97, r^{2}=0.99 ; 1.08, r^{2}=0.97\right.$; and $0.96, r^{2}=0.99$ respectively) (Fig. $3 \mathrm{~d}$ ).

a

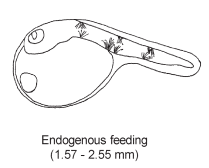

b
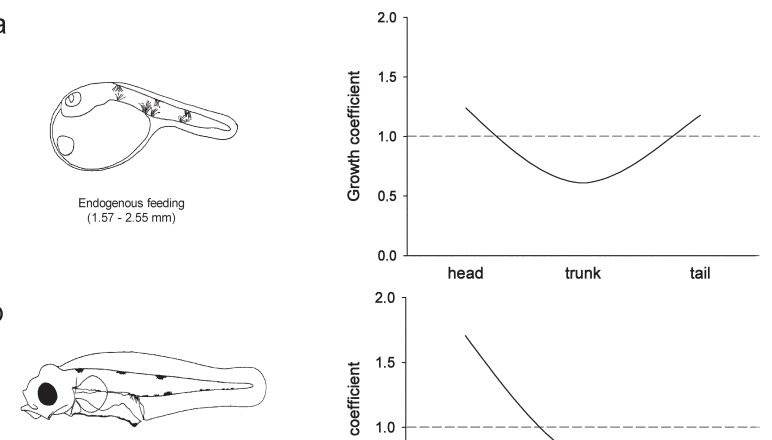

Prefexion larva
$(2.55-4.38 \mathrm{~mm}$ TL

C

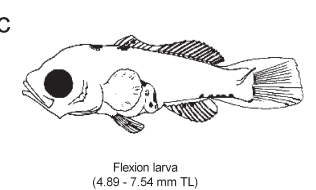

d
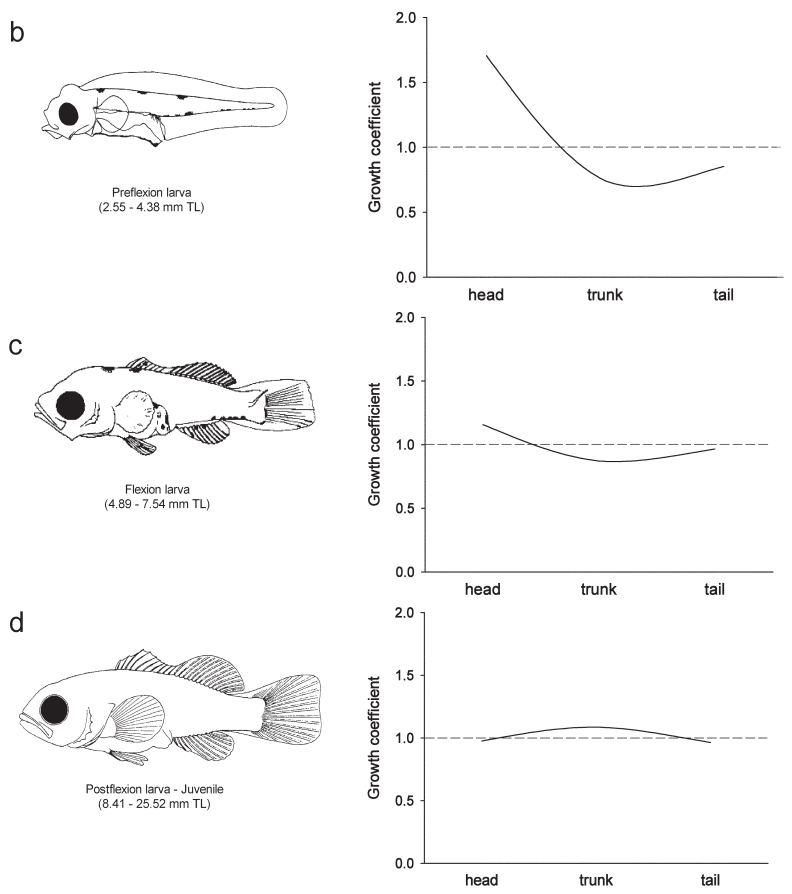

FIG. 3. - Growth coefficients of head, trunk and tail length during spotted sand bass development. Each graph represents the growth coefficients during a total length interval. Note the tendency to isometry during the transformation to juvenile. a
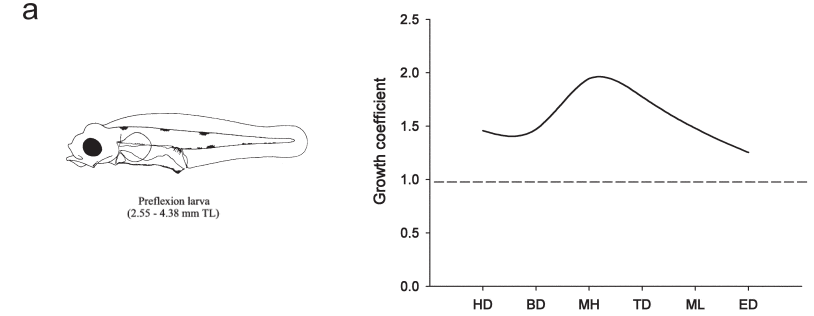

b
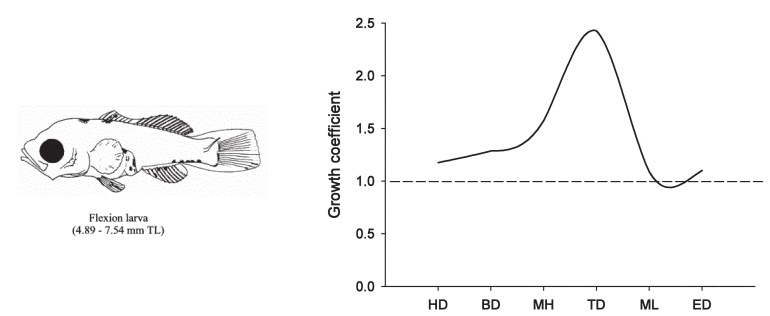

C
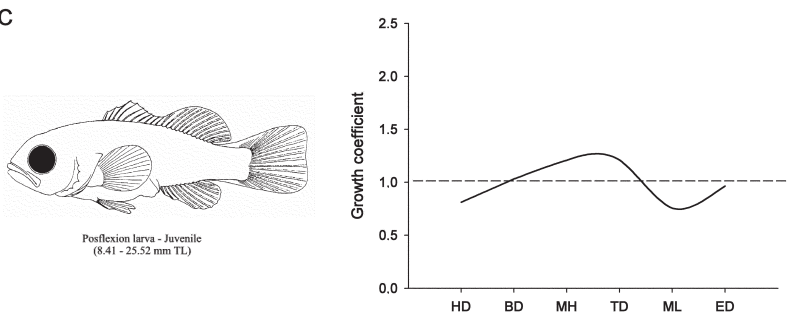

FIG. 4. - Growth coefficients of body proportions during spotted sand bass development. Each graph represents the growth coefficients during a total length interval. BD, body depth; $\mathrm{ED}$, eye diameter; $\mathrm{HD}$, head depth; $\mathrm{MH}$, musculature height; ML, mouth length; TD, tail depth.

During the preflexion stage the $\operatorname{HD}\left(b=1.45, r^{2}\right.$ $=0.99), \mathrm{BD}\left(b=1.47, r^{2}=0.98\right), \mathrm{MH}\left(b=1.94, r^{2}\right.$ $=0.99), \mathrm{TD}\left(b=1.77, r^{2}=0.99\right), \mathrm{ML}\left(b=1.48, r^{2}\right.$ $=0.99)$ and $\mathrm{ED}\left(b=1.25, r^{2}=0.98\right)$ showed positive allometric growth (Fig. 4a). During the flexion stage, the TD was the only measured character that showed an increment in the growth coefficient $(b$ $=2.42, r^{2}=0.99$ ) (Fig. 4b). During the postflexion stage there was a decrease in the growth coefficients of all measured body proportions. However, MH and TD both showed positive allometric growth $(b$ $=1.20, r^{2}=0.98$ and $b=1.21, r^{2}=0.99$ respectively), growth of BD and ED was isometric ( $b=$ $1.03, r^{2}=0.99$, and $b=0.96, r^{2}=0.99$ respectively), while the growth coefficients of HD and ML were negatively allometric $\left(b=0.81, r^{2}=0.99\right.$ and $b=$ $0.75, r^{2}=0.99$ respectively) (Fig. $4 \mathrm{c}$ ).

Inflection points for all the body measurements occurred during the flexion stage between days 12 and 16 , corresponding to the TL interval of 4.89 to $7.54 \mathrm{~mm}$ (Figs. 5a-e), except for the ED, which showed nearly isometric growth throughout the studied period (Fig. 5f). In every case there was a 

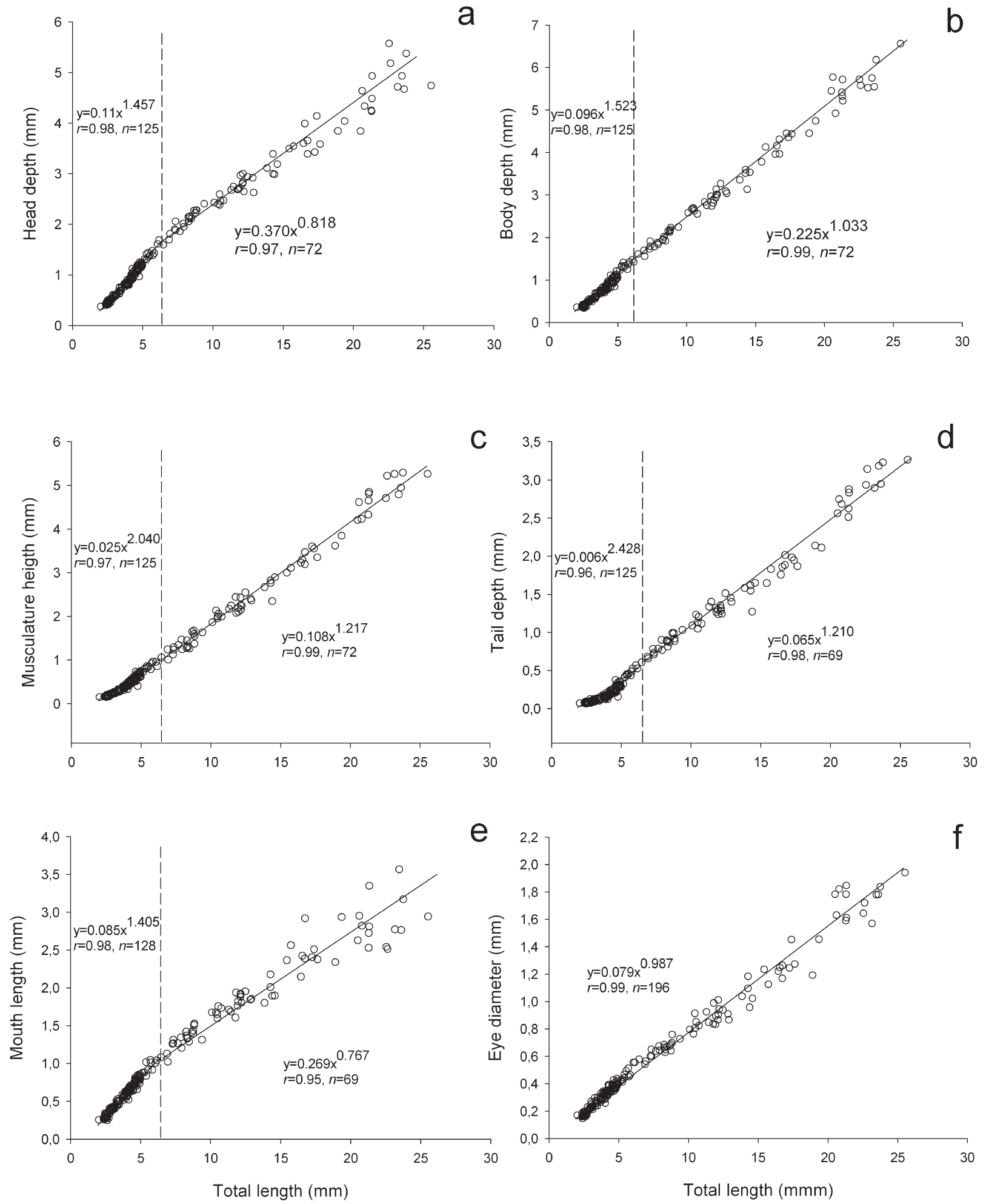

Fig. 5. - Allometric growth equations between measured body proportions and total length during spotted sand bass development. The dashed line represents the inflection point of growth.

reduction in the growth coefficients after the inflection point. Positive allometric growth was still observed for the $\mathrm{BD}, \mathrm{MH}$, and TD; however, the HD and ML changed to negative allometric growth.

\section{DISCUSSION}

The developmental stages and morphological changes reported in this study are in accordance 
with the ones previously described by Butler et al. (1982) in reared larvae of the same species. However, the size distribution during each developmental stage and total length at juvenile transformation differ between the two studies. Rearing conditions (i.e. feeding schedule and temperature) or genetic factors may explain these differences. Nevertheless, in both studies the transformation to a demersal juvenile occurs in less than 30 days. However, in order to clearly identify the length at transformation, osteological criteria should be considered since ossification, development of fin elements and squamation patterns are important landmarks for defining the onset of the juvenile period.

The changes in body form and consequently in functional development occur rapidly during early development. Indeed, the growth coefficients determined for the spotted sand bass larvae showed differential growth of body proportions during each developmental stage, which supports the hypothesis that in order to increase the probability of survival, a transition in ontogenetic priorities occurs during development (Osse et al., 1997; Osse and van den Boogaart, 2004).

From an incipient developmental state at hatching, differentiation processes take place during the endogenous nutrition period to ensure a successful transition from endogenous to exogenous nutrition. According to Osse and van den Boogaart (2004), the positive allometry of head length and tail length during the endogenous nutrition period reflects the early priority to develop those structures and organs related to vital functions such as feeding and swimming. It also indicates a more intense morphogenesis during this stage. In the head section, the early differentiation and development of the nervous (midbrain and hindbrain), sensory (free neuromasts, olfactory and photoreceptors) and feeding (mandibular structures) systems contribute to increasing the probability of prey detection and ingestion (Fuiman, 1983; Koumoundouros et al., 1999). In the tail section, faster tail growth contributes to improving swimming ability and predator avoidance (Fuiman, 1983) and has been explained as an adaptation to reduce and optimize the energetic costs of larval transport (Osse and van den Boogaart, 1995; 2004). It has also has been reported that ontogenetic behavioral transformations coincide with osteological development (Brown et al., 2001).

This pattern has also been observed in larvae of different teleost groups (Fuiman, 1983; Osse et al., 1997; van Snik et al., 1997; Koumoundouros et al., 1999; Gisbert, 1999; Gisbert et al., 2002; Osse and van den Boogart, 2004). It is likely that this developmental pattern during early fish ontogeny is genetically programmed.

The complete depletion of the yolk sac and oil globule indicates the onset of the preflexion stage (Kendall et al., 1984), during which there was a change in the growth coefficients of the head, trunk and tail segments. An increment in the growth coefficient of the head segment was observed presumably as a result of the development of the respiratory (branchial filaments) system. On the other hand, the growth coefficient of the tail segment changed to negative allometric growth, and the trunk segment remained negatively allometric. Despite the negative allometry of the trunk segment during the preflexion stage, the BD showed positive allometry. This may be due to the development of the digestive tract and associated glands. In the spotted sand bass, the development of mucosa folds and the coiling of the digestive tract begins during this stage (Peña et al., 2003). These changes along with an increase in enzymatic activity (Alvarez-González, 2003; Peña et al., 2009) enhance the digestive capability. Likewise, the tail segment showed negative allometric growth; however, the positive allometry of the TD and MH contribute to increasing the swimming capabilities, and together with the development of the ML allow the ingestion of bigger prey (Cunha and Planas, 1999).

An evident reduction in the growth coefficients of the head, trunk and tail segments was observed during the flexion stage. In the other body proportions there was also a reduction in the growth coefficients, except for the TD which increased significantly. This increment may correspond to the development and differentiation of the hypural plate (Ortíz-Galindo et al., 2000) and the caudal peduncle (Johnston and Hall, 2004). Furthermore, together with the disappearance of the larval finfold, and the development of the fins, a change in swimming style has been reported for other teleost larvae (van Snik et al., 1997; Gisbert, 1999; Gisbert et al., 2002). During the flexion stage, a main shift in the growth allometry also takes place. The inflection points of the measured body proportions occurred within a narrow TL interval (5.86 to $6.45 \mathrm{~mm}$ ). van Snik et al. (1997) also reported for Cyprinus carpio L. that the inflection points for several morphometric measurements occurred between the TL interval of 6.4 and $7.8 \mathrm{~mm}$. They 
suggested that this is related to a shift in swimming style from an anguilliform larval type to a sub-carangiform juvenile-type.

An overview of the growth coefficients showed an evident tendency to isometry for all the measured body proportions during the postflexion stage and the transformation to juvenile. This change to isometry has been considered as a natural transition in growth priorities since primary functions have been fulfilled during the early developmental stages (Osse and van den Boogaart, 2004). Based on our results, we can infer changes in ontogenetic priorities related to developmental stages in the spotted sand bass. During the yolk-sac (TL interval $=1.57$ to $2.55 \mathrm{~mm}$ ) and preflexion (TL interval $=2.55$ to $4.38 \mathrm{~mm}$ ) stages there is an evident priority given to increasing feeding and swimming capabilities by promoting accelerated growth for the head and tail segments. In the flexion stage (TL interval $=4.89$ to $7.54 \mathrm{~mm}$ ) there is a major reduction in growth coefficients, which indicates a shift in growth priorities. Once the growth priorities have been fulfilled, during the postflexion stage and transformation to juvenile a tendency to isometry is observed as in other teleost species (Fuiman, 1983; Osse and van den Boogaart, 2004).

\section{ACKNOWLEDGEMENTS}

Financial support was provided by the National Council for Science and Technology (CONACYT) of Mexico and by COFAA and PIFI of the Instituto Politécnico Nacional, Mexico.

\section{REFERENCES}

Alvarez-González, C.A. - 2003. Actividad enzimática digestiva y evaluación de dietas para el destete de larvas de la cabrilla arenera Paralabrax maculatofasciatus (Percoidei: Serranidae). $\mathrm{Ph}$. D. thesis. Centro Interdisciplinario de Ciencias Marinas. Mexico.

Alvarez-González, C. A., J.L. Ortíz-Galindo, S. Dumas, S. Martínez-Díaz, D.E. Hernández-Ceballos, T. Grayeb-Del Alamo, M. Moreno-Legorreta, R. Peña and R. Civera-Cerecedo. - 2001 Effect of stocking density on the growth and survival of spotted sand bass Paralabrax maculatofasciatus larvae in a closed recirculating system. J. World Aquacult. Soc., 32: 130-137.

Bailey, K. and E.D. Houde. - 1989. Predation on eggs and larvae of marine fish and the recruitment problem. Adv. Mar. Biol., 25: $1-83$.

Brown, A.L., M.S. Busby, K.L. Mier. - 2001. Walleye Pollock
Theragra chalcogramma during transformation from the larval to juvenile stage: otolith and osteological development. Mar. Biol., 139: 845-851.

Butler, J.L., H.D. Moser, G.S. Hageman and L.E. Nordgren. - 1982. Developmental stages of three California sea basses (Paralabrax, Pisces, Serranidae). CalCOFI Rep., 23: 252-268.

Cunha, I. and M. Planas. - 1999. Optimal prey size for early turbot larvae (Scophthalmus maximus L.) based on mouth and ingested prey size. Aquaculture, 175: 103-110.

Fuiman, L.A. - 1983. Growth gradients in fish larvae. J. Fish Biol., 23: $117-123$.

Gisbert, E. - 1999. Early development and allometric growth patterns in Siberian sturgeon and their ecological significance. $J$. Fish Biol., 54: 852-862.

Gisbert, E., G. Merino, J.B. Muguet, D. Bush, R.H. Piedrahita and D.E. Conklin. - 2002. Morphological development and allometric growth patterns in hatchery-reared California halibut larvae. J. Fish Biol., 61: 1217-1229.

Johnston, I.A. and T.E. Hall. -2004. Mechanisms of muscle development and responses to temperature change in fish larvae. In: J.J. Govoni (ed.), The Development of Form and Function in Fishes and the Question of Larval Adaptation, pp. 85-116. American Fisheries Society, Symposium 40, Bethesda, Maryland.

Kendall, A.W., E.H. Ahlstrom and H.G. Moser. - 1984. Early life history stages of fishes and their characters. In: Moser, H.G., Richards, W.J., Cohen, D.M., Fahay, M.P., Kendall, A.W., Richardson, S.L. (eds.). Ontogeny and systematics of fishes. American Society of Ichthyologists and Herpetologists, Special Publication No. 1, pp. 11-22. Allen Press Inc, Lawrence, Kansas, U.S.A.

Koumoundouros, G., P. Divanach and M. Kentouri. - 1999. Ontogeny and allometric plasticity of Dentex dentex (Osteichthyes: Sparidae) in rearing conditions. Mar. Biol., 135: 561-572.

Ortíz-Galindo, J.L., R. Peña, L. Perezgomez-Alvarez and J.L. Castro-Aguirre. - 2000. Desarrollo osteológico de la cabrilla arenera Paralabrax maculatofasciatus (Steindachner, 1868) (Percoidei: Serranidae). Mem. VII Congr. Nac. Ictiología. México, D.F.

Osse, J.W. and J.G.M. van den Boogaart. - 1995. Fish larvae, development, allometric growth, and the aquatic environment. Int. Council Exp. Sea. Mar. Sci. Symp., 201:21-34.

Osse, J.W. and J.G.M. van den Boogaart. - 2004. Allometric growth in Fish Larvae: Timing and Function. In: J.J. Govoni (ed.), The Development of Form and Function in Fishes and the Question of Larval Adaptation, pp. 167-194. American Fisheries Society, Symposium 40, Bethesda, Maryland.

Osse, J.W., J.G.M. van den Boogaart, G.M.J. van Snik and L. van der Sluys. - 1997. Priorities during early growth of fish larvae. Aquaculture, 155: 249-258.

Peña, R. and S. Dumas. - 2005. Effect of delayed first feeding on development and feeding ability of Paralabrax maculatofasciatus larvae. J. Fish Biol., 67: 640-561.

Peña, R., S. Dumas, Ortíz-Galindo, J.L. and Villalejo-Fuerte, M. 2003. Ontogenetic development of the digestive tract in reared spotted sand bass Paralabrax maculatofasciatus larvae. Aquaculture, 219: 633-644.

Peña, R., S. Dumas and C. Rodríguez-Jaramillo. - 2009. Development and distribution of intestinal enzymatic activity in Paralabrax maculatofasciatus (Steindachner, 1868) larvae fed live prey. Aquacult. Res. 40: 218-224.

Rosales-Velázquez, M.O. - 1997. Efecto de la alimentación sobre los desoves de la cabrilla arenera Paralabrax maculatofasciatus (Teleostei: Serranidae) mantenida en cautiverio. Tesis de Maestría. Centro Interdisciplianrio de Ciencias Marinas - Instituto Politécnico Nacional, La Paz, B.C.S. México.

van Snik, G.M.J., J.G.M. van den Boogaart and J.W.M. Osse. 1997. Larval growth patterns in Cyprinus carpio and Clarias gariepinus with attention to the fanfold. J. Fish Biol., 50: 13391352.

Received November 16, 2008. Accepted July 17, 2009.

Published online October 5, 2009. 